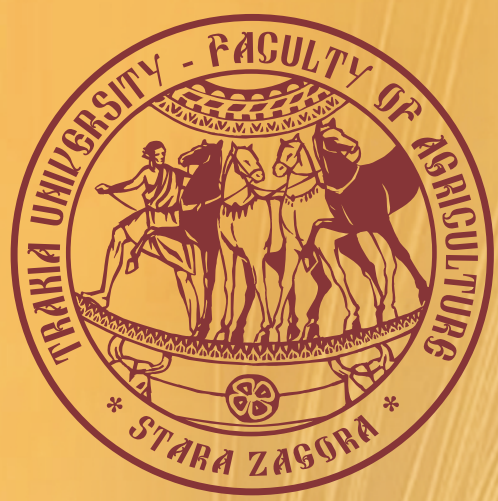

ISSN $1313-8820$ (print)

ISSN 1314 - 412X (online)

Volume 9 , Number 3

September 2017

\title{
AGRICULTURAL
}

\section{SCIENCE AND TECHNOLOGY}

\section{7}

An International Journal Published by Faculty of Agriculture, Trakia University, Stara Zagora, Bulgaria 


\section{Editor-in-Chief}

Georgi Petkov

Faculty of Agriculture

Trakia University, Stara Zagora

Bulgaria

E-mail: gpetkov@af.uni.sz.bg

\section{Co-Editor-in-Chief}

Dimitar Panayotov

Faculty of Agriculture

Trakia University, Stara Zagora

Bulgaria

\section{Editors and Sections}

\section{Genetics and Breeding}

Tsanko Yablanski (Bulgaria)

Atanas Atanasov (Bulgaria)

Svetlana Georgieva (Bulgaria)

Nikolay Tsenov (Bulgaria)

Max Rothschild (USA)

Ihsan Soysal (Turkey)

Horia Grosu (Romania)

Stoicho Metodiev (Bulgaria)

Bojin Bojinov (Bulgaria)

\section{Nutrition and Physiology}

Nikolai Todorov (Bulgaria)

Peter Surai (UK)

Ivan Varlyakov (Bulgaria)

George Zervas (Greece)

Vasil Pirgozliev (UK)

\section{Production Systems}

Radoslav Slavov (Bulgaria)

Dimitar Pavlov (Bulgaria)

Bogdan Szostak (Poland)

Banko Banev (Bulgaria)

Georgy Zhelyazkov (Bulgaria)

\section{Agriculture and Environment}

Martin Banov (Bulgaria)

Peter Cornish (Australia)

Vladislav Popov (Bulgaria)

Tarek Moussa (Egypt)

\section{Product Quality and Safety}

Stefan Denev (Bulgaria)

Vasil Atanasov (Bulgaria)

Roumiana Tsenkova (Japan)

\section{English Editor}

Yanka Ivanova (Bulgaria)
Scope and policy of the journal

Agricultural Science and Technology /AST/

- an International Scientific Journal of Agricultural and Technology Sciences is published in English in one volume of 4 issues per year, as a printed journal and in electronic form. The policy of the journal is to publish original papers, reviews and short communications covering the aspects of agriculture related with life sciences and modern technologies. It will offer opportunities to address the global needs relating to food and environment, health, exploit the technology to provide innovative products and sustainable development. Papers will be considered in aspects of both fundamental and applied science in the areas of Genetics and Breeding, Nutrition and Physiology, Production Systems, Agriculture and Environment and Product Quality and Safety. Other categories closely related to the above topics could be considered by the editors. The detailed information of the journal is available at the website. Proceedings of scientific meetings and conference reports will be considered for special issues.

\section{Submission of Manuscripts}

There are no submission / handling / publication charges.

All manuscripts written in English should be submitted as MS-Word file attachments via e-mail to editoffice@agriscitech.eu. Manuscripts must be prepared strictly in accordance with the detailed instructions for authors at the website

www.agriscitech.eu and the instructions on the last page of the journal. For each manuscript the signatures of all authors are needed confirming their consent to publish it and to nominate on author for correspondence.

They have to be presented by a submission letter signed by all authors. The form of the submission letter is available upon from request from the Technical Assistance or could be downloaded from the website of the journal. Manuscripts submitted to this journal are considered if they have submitted only to it, they have not been published already, nor are they under consideration for publication in press elsewhere. All manuscripts are subject to editorial review and the editors reserve the right to improve style and return the paper for rewriting to the authors, if necessary. The editorial board reserves rights to reject manuscripts based on priorities and space availability in the journal.

The journal is committed to respect high standards of ethics in the editing and reviewing process and malpractice statement. Commitments of authors related to authorship are also very important for a high standard of ethics and publishing. We follow closely the Committee on Publication Ethics (COPE), http://publicationethics.org/resources/guid elines

The articles appearing in this journal are indexed and abstracted in: DOI, EBSCO Publishing Inc., AGRIS (FAO) and DOAJ.

The journal is accepted to be indexed with the support of a project № BG051P00013.3.05-0001 "Science and business" financed by Operational Programme "Human Resources Development" of EU. The title has been suggested to be included in SCOPUS (Elsevier) and Electronic Journals Submission Form (Thomson Reuters).

The journal is freely available without charge to the user or his/her institution. Users can read, download, copy, distribute, print, search, or link to the full texts of the articles, or use them for any other lawful purpose, without asking prior permission from the publisher or the author.

This issue is printed with the financial support by Contract No DNP 0521/20.12.2016, financed from Fund 'Scientific Research' grant Bulgarian scientific Periodicals.

\section{Address of Editorial office:}

Agricultural Science and Technology Faculty of Agriculture, Trakia University

Student's campus, 6000 Stara Zagora

Bulgaria

Telephone: +35942699330 $+35942699446$

www.agriscitech.eu

Technical Assistance:

Nely Tsvetanova

Telephone: +359 42699446

E-mail:editoffice@agriscitech.eu 


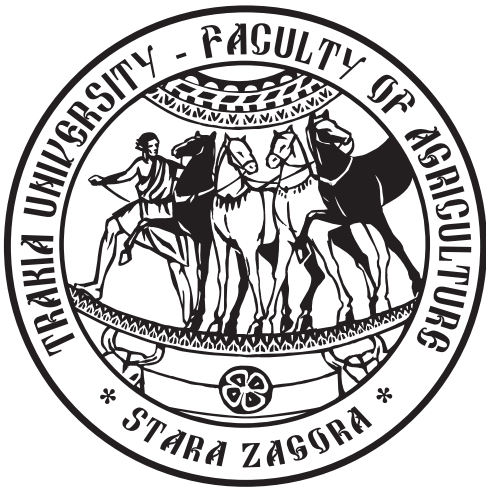

AGRICULTURAL

SCIENCE AND TECHNOLOGY

\section{7}

An International Journal Published by Faculty of Agriculture,

Trakia University, Stara Zagora, Bulgaria 


\title{
Short Communication
}

\section{Influence of elevated platform (wire-mesh or wooden) in the cage on domestic rabbit (Oryctolagus cuniculus) activity}

\author{
S. Peeva ${ }^{1 *}$, E. Raichev', D. Georgiev², A. Stefanov ${ }^{3}$ \\ ${ }^{1}$ Department of Animal Production - Non-ruminants and Other Animals, Faculty of Agriculture, Trakia University, 6000 Stara Zagora, Bulgaria, \\ ${ }^{2}$ Department of Biology and Aquaculture, Faculty of Agriculture, Trakia University, Stara Zagora, 6000, Bulgaria \\ ${ }^{3}$ Student Faculty of Veterinary Medicine, Trakia University, 6000 Stara Zagora, Bulgaria
}

(Manuscript received 29 June 2017; accepted for publication 12 August 2017)

\begin{abstract}
Placing an elevated platform in the cage of rabbits is an option to increase its area. The aim of this study was to determine whether raised platform affected the overall activity of breeding rabbits and to evaluate the influence of used material (wire-mesh or wood). Two experimental groups of three male Californian rabbits at four months of age, equal body mass and condition were formed. Their activity was examined in three cage types: without platforms, with wire-mesh platforms and with wooden platforms using camera traps. Separation of cage volume by means of an elevated platform increased the activity of breeding rabbits. The rabbit activity was also influenced by the platform material. It was almost three times higher when the platform was made from wood than from wire-mesh.
\end{abstract}

Keywords: Oryctolagus cuniculus, rabbits, hopping locomotion, cage volume

\section{Introduction}

Astandard barren cage provides only $1 \%$ of the home range of a rabbit group which naturally covers $50 \mathrm{~m}^{2}$ (Surridge et al., 1999; Hawkins, 2008). The young rabbits which will be used for breeding (future breeders) need more movement and space than those to be fattened. The space restrictions of standard cages $\left(2600 \mathrm{~cm}^{2}\right)$ frustrate normal hopping locomotion (Podberscek et al., 1991). The provision of enrichment in the cages led to a more efficient use of total floor space by dividing the cage into different functional areas (Buijs et al., 2011). Such an effect was described for platforms (Postollec et al., 2008). Welfare cages provide the rabbits at least $600 \mathrm{~cm}^{2}$ per animal. Rabbits need to stand on two legs to look around but conventional cages do not provide this opportunity (McBride, 1986; Dixon et al., 2010). Placing an elevated platform in the cage is an option to increase its area. However, this can also have a negative effect - worsening of the hygiene in the cage depending on the construction of the platform (EFSA, 2005). The aim of this study was to determine whether the presence of a raised platform affected the overall activity of breeding rabbits and to evaluate the influence of used material (wire-mesh or wood).

\section{Material and methods}

Three types of cages were constructed with the same parameters $(62 / 92 / 45 \mathrm{~cm})$. The first type of cages lacked platforms; the second were equipped with wire-mesh platforms at a height of 23 $\mathrm{cm}$ from the bottom, $62 / 40 \mathrm{~cm}$ of size, and the third type of cages wooden platforms of the same size and at the same height. Two experimental groups of three male Californian rabbits at four months of age, equal body mass and condition were formed. The third, control group included three animals of the same breed, sex and body mass that were housed in individual cages without a platform. All cages were uniformly equipped with feeders for pelleted feed, bottle-type drinkers and wooden boxes. Nine camera traps Keep Guard - 690EB were mounted on the back side of each cage. The devices recorded every movement at 10-minute intervals. The observation lasted four days ( 96 hours). The animals were housed in the cages three days earlier for adaptation to the experimental conditions. With the same operating mode of the nine cameras, the number of pictures in each cage was registered. It was used as an indicator of the locomotor activity of each group of animals. The experiment was repeated three days later with nine other animals of the same breed and sex.

\section{Results and discussion}

During the first experiment, the rabbits placed in cages with wire-mesh platforms exhibited by $25.18 \%$ higher activity than these from the control group, while the rabbits in cages with wooden platforms - by $73.38 \%$ higher (Table1). A similar tendency was shown by the results of the repetition $(27.32 \%$ higher activity in wiremesh platform cages and $81.16 \%$ in wooden platform cages).

The probable reason for the higher activity was the separation of cage volume into different functional areas by elevated platforms: hiding place, looking post (Hansen and Berthelsen, 2000; Hawkins, 2008). The wooden platform provides a more efficient separation of the cage volume and as a result rabbits were with higher level of

*e-mail: st.peeva@abv.bg 
Table1. Number of registered movements of Californian rabbits housed in three cage types: without platform, with wiremesh and wooden platforms and percentage of activity change compared to the control group over a 96-hours period

\begin{tabular}{|c|c|c|c|c|c|}
\hline \multirow[t]{2}{*}{ Number } & Control group (without platrorm) & \multicolumn{2}{|c|}{ Group with wire-mesh platform } & \multicolumn{2}{|c|}{ Group with wire-mesh platform } \\
\hline & Total number of photos & Total number of photos & $\%$ increase & Total number of photos & $\%$ increase \\
\hline Experiment I & 695 & 870 & 25.18 & 1205 & 73.38 \\
\hline Experiment II & 637 & 811 & 27.32 & 1154 & 81.16 \\
\hline
\end{tabular}

activity. Furthermore, wooden platforms combine floors and the presence of a footrest. Similarly, the wire-net platform with the manure tray provides the optimal environment for growing rabbits, as it expands available floor area and possibility of seeking cover when desired (Szendro et al., 2012). It has been reported that does prefered plastic mesh platforms and used them more often than wire-mesh platforms (Miko et al., 2014). Similarly to our results, does and their rabbits responded to the availability of an elevated platform by increasing their activity (Szendro et al., 2003). The cages with elevated platforms provide greater possibilities for movement which is beneficial from the viewpoint of animal welfare (Gerencser et al., 2016; Martino et al., 2016). However, this greater activity influences the oxidative status of the meat, decreasing the antioxidant content and worsening the lipid oxidation of rabbit meat (Gerencser et al., 2016). Hence, placing elevated platforms in rabbit's cages is appropriate for future breeders, not for rabbits for fattening.

\section{Conclusion}

Separation of the cage volume using an elevated platform increased the activity of breeding rabbits. The rabbit activity was influenced by the platform material.Wire-mesh platform increased rabbits activity with $25 \%$, and wooden platform - with $75 \%$.

\section{References}

Buijs St, Keeling L and Tuyttens F, 2011. Behaviour and use of space in fattening rabbits as influenced by cage size and enrichment. Applied Animal Behaviour Science, 134, 229-238.

Dixon L, Hardiman J and Cooper J, 2010. The effects of spatial restriction on the behaviour of rabbits (Oryctolagus cuniculus). Jourmal of Veterinary Behavior, 5, 302-308.

EFSA, 2005. The impact of current housing and husbandry systems on the health and welfare of farmed domestic rabbits. The EFSA Jourmal, 267, 1-31.

Gerencser Zs, Farkas T, Dal Bosco A, Filiou E, Matics Zs, Odermatt M, Paci G and Szendro Zs, 2016. The usage of multilevel platforms in growing rabbits housed in large pens as affected by platform material (wire-mesh vs plastic-mesh). Ethology and Welfare, $11^{\text {th }}$ World Rabbit Congress - June 15-18, 2016, Qingdao China.

Hansen $L$ and Berthelsen $H, 2000$. The effect of environmental enrichment on the behaviour of caged rabbits (Oryctolagus cuniculus). Applied Animal Behaviour Science, 68, 163-178.

Hawkins P, Hubrecht R, Buckwell A, Cubitt St, Howard B, Jackson $A$ and Poirier G, 2008. Refining rabbit care: A resource for those working with rabbits in research. RSPCA, West Sussex and UFAW, Herdfordshire.

Martino M, Mattioli S, Farkas P, Szendro Zs, Dal Bosco A, Ruggeri S, Matics Zs, Castellini C and Gerencser Zs, 2016. Carcass traits and meat quality of growing rabbits in pens with and without different multilevel platforms. World Rabbit Science, 24, 129138.

McBride E, 1986. Aspects of social and parental behaviour in the European rabbit (thesis), University College, London, Bloonsbury, UK.

Miko A, Matics Zs, Gerencser Zs, Odermatt M, Radnai I, Nagy I, Szendro K and Szendro Zs, 2014. Performance and welfare of rabbit does in various caging systems. Animal 8, 1146-1152.

Podberscek A, Blackshaw J and Beattie A, 1991. The behavior of group penned and individually cages laboratory rabbits. Applied Animal Behaviour Science, 28, 353-364.

Postollec G, Boilletot E, Maurice R and Michel V, 2008. The effect of pen size and an enrichment structure (elevated platform) on the performances and the behavior of fattening rabbits. Animal Welfare, 17, 53-59.

Surridge A, Bell D and Hewitt G, 1999. From population structure to individual behaviour: genetic analysis of social structure in the European wild rabbit (Oryctolagus cuniculus). Biological Journal of the Linnean Society, 68, 57-71.

Szendro Zs, Matics Zs, Odermatt M, Gerencser Zs, Nagy I, Szendro K and Dalle Zotte A, 2012. Use of different areas of pen by growing rabbits depending on the elevated platforms' floor-type. Animal, 6, 650-655.

Szendro Zs, McNitt J, Matics Zs, Miko A and Gerencser Zs, 2016. Alternative and enriched housing systems for breeding does: A review. World Rabbit ScienceAssociation, 24, 1-14. 
Reviews

Problems and achievements of cotton (Gossypium Hirsutum L.) weeds control

T. Barakova, G. Delchev

Achievements and problems in the weed control in grain sorghum (Sorghum Bicolor Moench.)

G. Delchev, M. Georgiev

\section{Genetics and Breeding}

Parthenogenetic responsiveness of sunflower hybrid combinations with expressed tolerance to herbicides

M. Drumeva, P. Yankov

In vitro propagation of oil-bearing rose (Rosa damascena Mill.)

V. Badzhelova

\section{Nutrition and Physiology}

Variation in the chemical composition and physical characteristics of grain from winter barley varieties

B. Dyulgerova, N. Dyulgerov, D. Dimova

Haematological and serum biochemical indices of broiler chickens fed raw sickle pod (Senna obtusifolia) seed meal

C. Augustine, I.D. Kwari, J.U. Igwebuike, S.B. Adamu

Prey size selectivity of pikeperch (Sander Lucioperca L.) fed with topmouth gudgeon (Pseudorasbora Parva Temminck \& Schlegel)

M. Gevezova-Kazakova, M. Yankova, T. Hubenova, A. Zaikov, G. Rusenov

Influence of organic nitrogen amendment, containing amino acids on the cellulase and xylanase, produced by Trichoderma spp. isolates

D. Draganova, I. Valcheva, Y. Kuzmanova, M. Naydenov

\section{Production Systems}

Justification of a method for determining the moment for switching on the level one signaling of filled grain harvester hoppers

G. Tihanov, B. Kolev, K. Trendafilov, N. Delchev, Y. Stoyanov

Mathematical approaches for assessment and classification of the European Union member states based on the average yield of vegetables for the period 1961-2014

N. Keranova 
Present status of Zymoseptoria tritici (Mycospharella graminicola /Fuckel/ Schroter) of the wheat cultures in the Republic of Macedonia

I. Karov, E. Arsov

\section{Agriculture and Environment}

Influence of basic agrotechnical activities on the productivity and yield of Triticum monococcum $\mathrm{L}$.

S. Stamatov, K. Uzundzhalieva, E. Valchinova, G. Desheva, P. Chavdarov, B. Kyosev, T. Cholakov, R.

Ruseva, N. Velcheva

Avifauna abundance and diversity in Jos wildlife park, Nigeria

B.T. Kwaga, D. lliya, A. Ali, D. Khobe

Ecological analysis of the flora in the 'Chinarite' protected area - Rodopi municipality, Bulgaria

L. Dospatliev, M. Lacheva

Product Quality and Safety

Food emulsions with amidated pectin from celery (Apium graveolens var. rapaceum D. C.) tubers Iv. Petrova, N. Petkova, M. Ognyanov, Ap. Simitchiev, M. Todorova, P. Denev

M. Tonchev, T. Atanasov, A. Todorova, Ts. Atanasova, N. Shtrankova, M. Momchilova G. Zsivanovits

\section{Short Communication}

Influence of elevated platform (wire-mesh or wooden) in the cage on domestic rabbit (Oryctolagus cuniculus) activity

S. Peeva, E. Raichev, D. Georgiev, A. Stefanov 


\section{Instruction for authors}

\section{Preparation of papers}

Papers shall be submitted at the editorial office typed on standard typing pages (A4, 30 lines per page, 62 characters per line). The editors recommend up to 15 pages for full research paper ( including abstract references, tables, figures and other appendices)

The manuscript should be structured as follows: Title, Names of authors and affiliation address, Abstract, List of keywords, Introduction, Material and methods, Results, Discussion, Conclusion, Acknowledgements (if any), References, Tables, Figures.

The title needs to be as concise and informative about the nature of research. It should be written with small letter /bold, 14/ without any abbreviations.

Names and affiliation of authors The names of the authors should be presented from the initials of first names followed by the family names. The complete address and name of the institution should be stated next. The affiliation of authors are designated by different signs. For the author who is going to be corresponding by the editorial board and readers, an E-mail address and telephone number should be presented as footnote on the first page. Corresponding author is indicated with *

Abstract should be not more than 350 words. It should be clearly stated what new findings have been made in the course of research. Abbreviations and references to authors are inadmissible in the summary. It should be understandable without having read the paper and should be in one paragraph.

Keywords: Up to maximum of 5 keywords should be selected not repeating the title but giving the essence of study.

The introduction must answer the following questions: What is known and what is new on the studied issue? What necessitated the research problem, described in the paper? What is your hypothesis and goal?

Material and methods: The objects of research, organization of experiments, chemical analyses, statistical and other methods and conditions applied for the experiments should be described in detail. A criterion of sufficient information is to be possible for others to repeat the experiment in order to verify results.

Results are presented in understandable tables and figures, accompanied by the statistical parameters needed for the evaluation. Data from tables and figures should not be repeated in the text. Tables should be as simple and as few as possible. Each table should have its own explanatory title and to be typed on a separate page. They should be outside the main body of the text and an indication should be given where it should be inserted.

Figures should be sharp with good contrast and rendition. Graphic materials should be preferred. Photographs to be appropriate for printing. Illustrations are supplied in colour as an exception after special agreement with the editorial board and possible payment of extra costs. The figures are to be each in a single file and their location should be given within the text.

Discussion: The objective of this section is to indicate the scientific significance of the study. By comparing the results and conclusions of other scientists the contribution of the study for expanding or modifying existing knowledge is pointed out clearly and convincingly to the reader. Conclusion: The most important consequences for the science and practice resulting from the conducted research should be summarized in a few sentences. The conclusions shouldn't be numbered and no new paragraphs be used. Contributions are the core of conclusions. References:

In the text, references should be cited as follows: single author: Sandberg (2002); two authors: Andersson and Georges (2004); more than two authors: Andersson et al.(2003). When several references are cited simultaneously, they should be ranked by chronological order e.g.: (Sandberg, 2002; Andersson et al., 2003; Andersson and Georges, 2004).

References are arranged alphabetically by the name of the first author. If an author is cited more than once, first his individual publications are given ranked by year, then come publications with one co-author, two co-authors, etc. The names of authors, article and journal titles in the Cyrillic or alphabet different from Latin, should be transliterated into Latin and article titles should be translated into English. The original language of articles and books translated into English is indicated in parenthesis after the bibliographic reference $($ Bulgarian $=\mathrm{Bg}$, Russian $=\mathrm{Ru}$, Serbian $=\mathrm{Sr}$, if in the Cyrillic, Mongolian =
Mo, Greek = Gr, Georgian = Geor., Japanese $=\mathrm{Ja}$, Chinese $=\mathrm{Ch}$, Arabic $=\mathrm{Ar}$, etc.)

The following order in the reference list is recommended:

Journal articles: Author(s) surname and initials, year. Title. Full title of the journal, volume, pages. Example:

Simm G, Lewis RM, Grundy B and Dingwall WS, 2002. Responses to selection for lean growth in sheep. Animal Science, 74, 39-50

Books: Author(s) surname and initials, year. Title. Edition, name of publisher, place of publication. Example:

Oldenbroek JK, 1999. Genebanks and the conservation of farm animal genetic resources, Second edition. DLO Institute for Animal Science and Health, Netherlands.

Book chapter or conference proceedings: Author(s) surname and initials, year. Title. In: Title of the book or of the proceedings followed by the editor(s), volume, pages. Name of publisher, place of publication. Example:

Mauff G, Pulverer G, Operkuch W, Hummel K and Hidden C, 1995. C3variants and diverse phenotypes of unconverted and converted C3. In: Provides of the Biological Fluids (ed. $\mathrm{H}$. Peters), vol. 22, 143-165, Pergamon Press. Oxford, UK.

Todorov N and Mitev J, 1995. Effect of level of feeding during dry period, and body condition score on reproductive performance in dairy cows, IX $X^{\text {th }}$ International Conference on Production Diseases in Farm Animals, September 11-14, Berlin, Germany.

Thesis:

Hristova D, 2013. Investigation on genetic diversity in local sheep breeds using DNA markers. Thesis for PhD, Trakia University, Stara Zagora, Bulgaria, (Bg).

The Editorial Board of the Journal is not responsible for incorrect quotes of reference sources and the relevant violations of copyrights.

\section{Animal welfare}

Studies performed on experimental animals should be carried out according to internationally recognized guidelines for animal welfare. That should be clearly described in the respective section "Material and methods". 


\section{AGRICULTURAL \\ SCIENCE AND TECHNOLOGY}

Volume 9, Number 3

September 2017
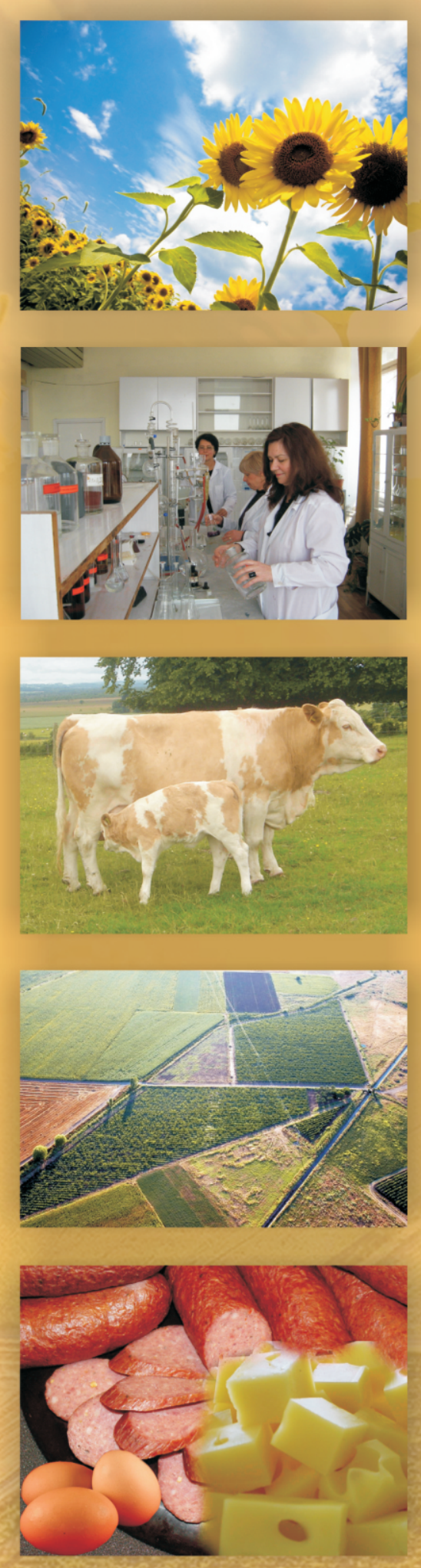

Journal web site: 